\title{
Alcohol-based surgical hand preparation: translating scientific evidence into clinical practice
}

Gilberto G. Gaspar ${ }^{1,6^{*}}$, Mayra G. Menegueti ${ }^{1}$, Ana Elisa R. Lopes ${ }^{1}$, Roberto O. C. Santos², Thamiris R. de Araújo ${ }^{3}$, Aline Nassiff3', Lécio R. Ferreira' ${ }^{1}$, Maria Eulalia L. V. Dallora ${ }^{4}$, Silvia R. M. S. Canini ${ }^{3}$ and Fernando Bellissimo-Rodrigues ${ }^{5}$

\begin{abstract}
Background: Although alcohol-based surgical hand preparation offers potential advantages over the traditional surgical scrubbing technique, implementing it may be challenging due to resistance of surgeons in changing their practice. We aimed to implement alcohol-based surgical hand preparation in the hospital setting evaluating the impact of that on the quality and duration of the procedure, as well as on the prevention of surgical site infections.

Methods: A quasi-experimental study conducted at a tertiary-care university hospital from April 01 to November 01, 2017. Participants were cardiac and orthopedic surgical teams $(n=56)$ and patients operated by them $(n=231)$. Intervention consisted of making alcohol-based handrub available in the operating room, convincing and training surgical teams for using it, promoting direct observation of surgical hand preparation, and providing aggregated feedback on the quality of the preparation. The primary study outcome was the quality of the surgical hand preparation, inferred by the compliance with each one of the steps predicted in the World Health Organization (WHO) technique, evaluated through direct observation. Secondary study outcome was the patient's individual probability of developing surgical site infection in both study periods. We used the Wilcoxon for paired samples and McNemar's test to assess the primary study outcome and we build a logistic regression model to assess the secondary outcome.
\end{abstract}

Results: We observed 534 surgical hand preparation events. Among 33 participants with full data available for both study periods, we observed full compliance with all the steps predicted in the WHO technique in $0.03 \%(1 / 33)$ of them in the pre-intervention period and in $36.36 \%(12 / 33)$ of them in the intervention period (OR:12.0, 95\% Cl: 2. 4-59.2, $p=0.002$ ). Compared to the pre-intervention period, the intervention reduced the duration of the preparation ( $4.8 \mathrm{~min}$ vs $2.7 \mathrm{~min}$, respectively; $p<0.001$ ). The individual risk of developing a surgical site infection did not significantly change between the pre-intervention and the intervention phase (Adjusted RR $=0.66 ; 95 \% \mathrm{Cl} 0.16-2.70, p=0.563$ ).

Conclusion: Our results demonstrate that, when compared to the traditional surgical scrub, alcohol-based surgical hand preparation improves the quality and reduces the duration of the preparation, being at least equally effective for the prevention of surgical site infections.

\footnotetext{
* Correspondence: ggaspar@hcrp.usp.br

${ }^{1}$ Infection Control Service, University Hospital of the Ribeirão Preto Medical

School, University of São Paulo, Ribeirão Preto, SP, Brazil

שUniversity Hospital of Ribeirão Preto Medical School, Avenida Bandeirantes,

3900 - Vila Monte Alegre, Ribeirão Preto, SP 14048-900, Brazil

Full list of author information is available at the end of the article
}

(c) The Author(s). 2018 Open Access This article is distributed under the terms of the Creative Commons Attribution 4.0 International License (http://creativecommons.org/licenses/by/4.0/), which permits unrestricted use, distribution, and reproduction in any medium, provided you give appropriate credit to the original author(s) and the source, provide a link to the Creative Commons license, and indicate if changes were made. The Creative Commons Public Domain Dedication waiver (http://creativecommons.org/publicdomain/zero/1.0/) applies to the data made available in this article, unless otherwise stated. 


\section{Background}

Surgical site infection (SSI) is a worldwide concern. A study conducted in 16 European countries identified that $20 \%$ of all notified healthcare-associated infections were related to surgical procedures [1]. In Florida, SSI represented one-third of all cases of healthcare-associated infections [2].

Surgical hand preparation is recommended by both the Centers for Disease Control and Prevention (CDC) and the World Health Organization (WHO) for preventing SSI in all kinds of surgical procedures [3]. There are two well-recognized methods for performing surgical hand preparation. The most traditional one is scrubbing hands and forearms with antimicrobial soap, usually $2 \%$ chlorhexidine or $10 \%$ povidone-iodine (PVPI). More recently, alcohol-based surgical hand preparation has been proposed as an alternative to surgical scrub [3-8]. Among potential advantages of the alcohol-based procedure are: less skin irritation, less time-consuming, economy of tap water, and more potent antimicrobial effect [9].

However, surgeons may be skeptical about adopting alcohol-based surgical hand preparation, and this may represent a challenge for implementing such a strategy in the operating room. A study carried out among 156 healthcare professionals in a medical center in Taiwan identified that a higher number of nurses employed alcohol-based handrub (ABHR) for surgical hand preparation as compared to surgeons. The authors attributed this finding to the greater familiarity of surgeons with the traditional surgical hand preparation technique and to their higher reliability on the antiseptic effect thereof [10].

Therefore, studies performed in the real world scenario are necessary to confirm the benefits of using ABHR for surgical hand preparation, predicted mostly by lab studies. Implementation research studies entail: (i) testing strategies to face obstacles and (ii) determining the best strategy to introduce innovations or to promote sustainable changes [11].

The present study aimed to implement the exchange of using antimicrobial soap for using ABHR in the context of surgical hand preparation and to evaluate the impact of that on the quality and duration of the procedure, as well as on the prevention of surgical site infections.

\section{Methods}

This quasi-experimental study was conducted from April 01 to November 01, 2017 in a tertiary-care public-affiliated university hospital in Brazil. The Research Ethics Committee of the study institution approved its protocol before the study implementation $\left(n^{\circ} 64,964,217.9 .0000 .5440\right)$.
The study population consisted of all members of the cardiac and orthopedic surgical teams of the study facility and all patients operated by them during the study period. Each patient was included just one time in the study, so re-operations during the study period were not considered in the data analysis.

In the pre-intervention period, which lasted 3 months, traditional surgical scrub was performed with antimicrobial soap (either $2 \%$ chlorhexidine or $10 \%$ PVPI) before every surgery and ABHR was not available for surgical hand preparation. Direct observation of the procedures was implemented as a part of the data collection.

Just after the pre-intervention period, we started the implementation period, which lasted 1 month, and during it no data was collected. The intervention consisted of making ABHR available in the operating room, convincing and training the selected surgical teams for using it, promoting direct observation of surgical hand preparation, and providing them aggregated feedback on the quality of the preparation. The training consisted of a $4 \mathrm{~h}$ workshop, repeated five times, when the scientific literature about surgical hand preparation was reviewed and the participants were instructed about how to apply ABHR for this purpose, according to the WHO technique. To ensure the covering of all hand and forearms surface, we asked all participants to apply a fluorescent ABHR simulating the surgical hand preparation, which was afterwards revealed by a fluorescence apparatus.

Just after the implementation period, the intervention period began, and the data collection re-started. The intervention period also lasted 3 months.

The primary study outcome was the quality of the surgical hand preparation, inferred by the compliance with each one of the steps predicted in the WHO technique, evaluated through direct observation in the operating room. Secondary study outcome was the patient's individual probability of developing SSI in both study periods.

The following instruments were employed for data collection:

1) Surgical site infection (SSI) - we followed up operated patients for 1 month to verify whether they had developed SSI or not, according to the CDC criteria, including post-discharge surveillance. Patients were screened by an infection control nurse, and SSI episodes were confirmed by an infectious disease specialist of the Infection Control Service.

2) Risk factors for SSI - an instrument containing the following items was designed: study phase, surgical procedure, extracorporeal circulation time (min), surgical time (min), American Society of Anesthesiologists physical status classification system (ASA), comorbidities, use of immunosuppressive 
drugs, Body Mass Index (BMI), preoperative hospital stay (in days), presence of infection before the surgery, antibiotic prophylaxis, surgical complications and SSI by a multidrugresistant microorganism (carbapenem-resistant Enterobacteria, Pseudomonas spp., or Acinetobacter baumannii; methicillin-resistant Staphylococcus aureus; or vancomycin-resistant Enterococcus spp.). Two investigators from the Infection Control Service collected these data.

3) Surgical hand-preparation quality assessment - an instrument based on the WHO technique and framing the following items was designed: time spent on surgical hand preparation, use of jewelry (e.g., rings, wristwatch, and bracelets), short nails, and compliance with all the antisepsis steps (palm to palm; right palm over back of left hand and viceversa; interdigital spaces, thumb, nails, fingertips, wrist, and forearm). Two investigators with extensive training in hand hygiene and surgical hand preparation performed these observations in both study periods.

Taking into account the previously unknown baseline status of the quality of the surgical hand preparation (primary study outcome) in the study facility, we could not estimate a sample size for the study. The period of 3 months for the pre-intervention and 3 months for the intervention was chosen for convenience. Data were analyzed with the STATA $\mathrm{SE}^{\oplus}$ software version 14 . First, a descriptive analysis was accomplished. Then, we calculated the weighted average for each surgical team member of the compliance with each one of the steps of the WHO technique for surgical hand preparation (primary study outcome) and we used the Wilcoxon test for paired samples to compare it between the two study periods. We also used McNemar's test to compare full compliance with the WHO technique observed before and after the intervention. Finally, we build a logistic regression model to assess the secondary study outcome (SSI risk) on the patient level, adjusting it for surrogate markers of baseline severity status, such as pre-operative length of stay, ASA score, and other potential risk factors for SSI implicated in univariate analysis $(p<0.10)$.

\section{Results}

All cardiac and orthopedic surgery staff members agreed to participate in the study and were included in the pre-intervention and intervention phases, totaling 56 participants. All the 231 patients who had undergone cardiac (85 patients) or orthopedic (146 patients) surgeries during the study period were also included.

Table 1 contains a descriptive analysis of selected demographical and clinical characteristics of the patients operated in pre-intervention (132 patients) and intervention (99 patients) phases. Although a reasonable balance was observed for most of these variables between the two study periods, we have detected some important differences. Median age was higher in the pre-intervention (53.7 years old) than in the intervention phase (46.9 years old). Orthopedic surgery was less frequent in the pre-intervention $(57.6 \%)$ than in the intervention phase (70.7\%). The average duration of the procedures was shorter in the pre-intervention (median time: $175 \mathrm{~min}$ ) compared to the intervention phase (median time: $240 \mathrm{~min})$. Technical complications during procedure were more frequent in the pre-intervention phase $(3.8 \%$ vs $1 \%)$ than in the intervention phase. In addition, finally, post-discharge follow-up reached more patients in the pre-intervention $(86.4 \%)$ than in the intervention phase $(73.7 \%)$.

\section{Surgical hand preparation quality assessment}

We directly observed 534 surgical hand preparation events. In the pre-intervention phase, 303 events were observed, and in most of them $2 \%$ chlorhexidine $(n=180)$ was employed for surgical scrub and, in the remaining events, 10\% PVPI $(n=123)$ was used. In the intervention phase, we observed 231 events of alcohol-based surgical hand preparation (Table 2). Compliance with most of the steps predicted by the WHO technique did not significantly varied between the two study periods. However, average compliance with the scrubbing of the thumb in the pre-intervention period $(86.2 \%)$ was lower than the rubbing of the thumb in the intervention period (96.9\%), and that difference was borderline statistically significant $(p=0.052)$. Nail scrubbing was observed in only $33.7 \%$ of events when chlorhexidine was employed and in only $41.5 \%$ of the events when PVPI was used. Interestingly, hands rinsing at the end of surgical hand preparation was performed only in $72.3 \%$ of the events in which PVPI was used. Another problem detected in the scrubbing period was that only 13.5 and $18.0 \%$ of the participants did not get back to hands after scrubbing the forearms, while using chlorhexidine and PVPI, respectively.

Considering a subset of 33 participants with full data available for both study periods, we observed a full compliance with all the steps predicted in the WHO technique for surgical hand preparation in $0.03 \%$ (1/33) of them in the pre-intervention period and in $36.36 \%$ $(12 / 33)$ of them in the intervention period (OR:12.0; 95\% CI: 2. 4-59.2; $p=0.002$ ).

The median scrubbing time was $4.8 \mathrm{~min}$ when the surgical team used chlorhexidine, and $4.9 \mathrm{~min}$ when they used PVPI. This was significantly longer than the median 2.7 min spent on rubbing hands and forearms, in the intervention period $(p=0.001)$. 
Table 1 Demographical and clinical aspects of the patients operated in the pre-intervention and intervention phases of the study

\begin{tabular}{|c|c|c|c|c|}
\hline \multirow[t]{2}{*}{ Patients characteristics } & \multicolumn{2}{|c|}{$\begin{array}{l}\text { Pre-intervention phase } \\
\text { Surgical scrub } \\
(n=132)\end{array}$} & \multicolumn{2}{|c|}{$\begin{array}{l}\text { Intervention phase } \\
\text { Alcohol-based surgical hand preparation } \\
(n=99)\end{array}$} \\
\hline & Number & Percent & Number & Percent \\
\hline \multicolumn{5}{|l|}{ Sex } \\
\hline Male & 74 & 56.0 & 62 & 62.6 \\
\hline Female & 58 & 44.0 & 37 & 37.4 \\
\hline Age (years) ${ }^{a}$ & \multicolumn{2}{|c|}{$53.7(25.0-65.9)$} & \multicolumn{2}{|c|}{$46.9(20.4-63.5)$} \\
\hline \multicolumn{5}{|l|}{ Surgical specialty } \\
\hline Orthopedics & 76 & 57.6 & 70 & 70.7 \\
\hline Cardiac & 56 & 42.4 & 29 & 29.3 \\
\hline Post-discharge follow-up & 114 & 86.4 & 73 & 73.7 \\
\hline Duration of surgery (min) ${ }^{a}$ & \multicolumn{2}{|c|}{$180(122-263)$} & \multicolumn{2}{|c|}{$200(130-255)$} \\
\hline Duration of extracorporeal circulation $(\min )^{a}(n=41)$ & \multicolumn{2}{|c|}{$115(80-140.5)$} & \multicolumn{2}{|c|}{$125(95-155)$} \\
\hline Preoperative length of stay (days) ${ }^{a}$ & \multicolumn{2}{|l|}{$2(1-8)$} & \multicolumn{2}{|l|}{$2(1-4)$} \\
\hline Body Mass Index - BMI & \multicolumn{2}{|c|}{$26.7(23.8-31.7)$} & \multicolumn{2}{|c|}{$27.2(23.2-30.5)$} \\
\hline Technical complication during procedure & 5 & 3.8 & 1 & 1 \\
\hline Urgent procedure & 8 & 6 & 8 & 8.1 \\
\hline Chronic hepatopathy & 2 & 1.5 & 5 & 5 \\
\hline Malignancy & 10 & 7.6 & 5 & 5 \\
\hline Diabetes Mellitus & 32 & 24.2 & 27 & 27.3 \\
\hline Use of immunosuppressive drug & 5 & 3.8 & 2 & 2 \\
\hline Smoking & 31 & 23.5 & 20 & 20.2 \\
\hline
\end{tabular}

${ }^{\text {a Median (interquartile range) }}$

Table 2 Percentage of weighted average compliance with each one of the steps of the WHO technique for surgical hand preparation according to the study phase and product employed

\begin{tabular}{|c|c|c|c|c|}
\hline \multirow{2}{*}{$\begin{array}{l}\text { Compliance with each one of } \\
\text { the steps of the } \mathrm{WHO} \text { technique } \\
\text { for surgical hand preparation }\end{array}$} & \multicolumn{2}{|l|}{$\begin{array}{l}\text { Pre-intervention phase } \\
(n=303)\end{array}$} & \multirow{2}{*}{$\begin{array}{l}\text { Intervention phase } \\
(n=231) \\
\text { Alcohol-based surgical } \\
\text { hand preparation }(\%) \\
(n=231)^{\mathbf{b}}\end{array}$} & \multirow[t]{2}{*}{ P-Value ${ }^{c}$} \\
\hline & $\begin{array}{l}\text { Surgical scrub with } 2 \% \\
\text { chlorhexidine (\%) } \\
(n=180)^{\mathbf{a}}\end{array}$ & $\begin{array}{l}\text { Surgical scrub with } 10 \% \\
\text { PVPI }(\%) \\
(n=123)^{\mathbf{b}}\end{array}$ & & \\
\hline Removed jewelry & 99.4 & 100 & 100 & 1.000 \\
\hline Short nails & 95 & 100 & 97.8 & 0.341 \\
\hline Finger & 96.6 & 95.9 & 98.2 & 0.762 \\
\hline Palm & 100 & 100 & 99 & 0.157 \\
\hline Back of hand & 96.6 & 97.4 & 98.2 & 0.946 \\
\hline Interdigital space & 82.1 & 85.5 & 93 & 0.948 \\
\hline Thumb & 85.7 & 87.2 & 96.9 & 0.052 \\
\hline Wrist & 95.5 & 98.3 & 99.1 & 0.247 \\
\hline $\begin{array}{l}\text { Did not get back to hands after } \\
\text { donning forearms }\end{array}$ & 13.5 & 18 & NA & NA \\
\hline Nail scrubbing & 33.7 & 41.5 & NA & NA \\
\hline Hands rinsing & 98.8 & 72.3 & NA & NA \\
\hline Time (min) & 4.8 & 4.9 & 2.7 & 0.001 \\
\hline
\end{tabular}

NA not applicable

${ }^{a}$ The number of surgical hand preparation events observed per participant ranged from 1 to 24

${ }^{\mathbf{b}}$ The number of surgical hand preparation events observed per participant ranged from 1 to 16

'Comparison between the pre-intervention and intervention phases by the Wilcoxon for paired samples test 
Analysis of potential risk factors for surgical site infection We analyzed all 231 patients operated during the study period. Among patients operated in the pre-intervention period, $8.3 \%$ (11/132) developed SSI, while during the intervention period, SSI rate was reduced to $4.0 \%$ (4/99), although those differences did not reach statistical significance $(\mathrm{RR}=0.48,95 \%$ CI $0.16-1.48)$.

Table 3 exhibits the univariate analysis of the potential risk factors for SSI observed during the study implementation. According to that analysis, no variable was implicated as a predictor of SSI and the alcohol-based surgical hand preparation, implemented in the intervention period, was not considered to impact on the individual probability of developing SSI ( $\mathrm{RR}=0.48,95 \%$ CI $0.16-1.48, p=0.281$ ).

Table 4 presents the multivariate analysis of the impact that alcohol-based surgical hand preparation could have over the individual probability of developing SSI, adjusted for pre-operative length of stay and ASA score. This analysis was performed for a subset of 150 patients, for whom all the data, including ASA score, was available. According to that, alcohol-based surgical hand preparation was not predictor nor protective against the individual risk of developing SSI (adjusted $\mathrm{RR}=0.66,95 \%$ CI 0. 16-2.70, $p=0.563$ ).

The incidence of SSI caused by multidrug-resistant microorganisms was $6.06 \%(8 / 132)$ in the pre-intervention period, dropping to $1.01 \%(1 / 99)$ in the intervention period $(\mathrm{RR}=0.17,95 \%$ CI 0. 21-1.31, $p=0.082)$.

\section{Difficulties faced during implementation of an ABHR for surgical hand preparation}

Two surgeons, one of the orthopedic surgery staff and another of the cardiac surgery staff, at first, reported that they did not rely on the ABHR effectiveness. Therefore, we scheduled meetings to show them that ABHR was actually efficient for surgical hand preparation. The professionals received all the information via email or printed articles. After this approach, these two surgeons complied with the use of ABHR during the intervention phase.

\section{Discussion}

Many advantages of using ABHR for surgical hand preparation have been proposed by scientific literature, mostly based on laboratory-based studies [12-16].

Table 3 Univariate statistical analysis of risk factors for surgical site infection (SSI) among 231 patients operated during the study period

\begin{tabular}{|c|c|c|c|c|c|}
\hline \multirow[t]{2}{*}{ Variable } & \multicolumn{2}{|c|}{ Patients characteristics } & \multirow{2}{*}{$\begin{array}{l}\text { With SSI } \\
(n=15)\end{array}$} & \multirow{2}{*}{$\begin{array}{l}\text { Without SSI } \\
(n=216)\end{array}$} & \multirow[t]{2}{*}{ Relative risk $(95 \% \mathrm{Cl})$ or $p$-value } \\
\hline & Situation & Total n (\%) & & & \\
\hline \multirow[t]{2}{*}{ Chronic Hepatopathy } & Present & $4(1.7 \%)$ & $1(6.6 \%)$ & $3(1.3 \%)$ & $4.05(0.68-23.80)$ \\
\hline & Absent & $227(98.3 \%)$ & & & \\
\hline \multirow[t]{2}{*}{ Malignance } & Present & $15(6.5 \%)$ & $1(6.6 \%)$ & $14(6.4 \%)$ & $1.02(0.14-7.30)$ \\
\hline & Absent & $216(93.5 \%)$ & & & \\
\hline \multirow[t]{2}{*}{ Diabetes Mellitus } & Present & $59(25.5 \%)$ & $2(13.3 \%)$ & $57(26.3 \%)$ & $0.44(0.10-1.92)$ \\
\hline & Absent & $172(74.4 \%)$ & & & \\
\hline \multirow[t]{2}{*}{ Use of immunosuppressive drugs } & Present & $7(3 \%)$ & $1(6.6 \%)$ & $6(2.7 \%)$ & $2.28(0.34-15.04)$ \\
\hline & Absent & $224(97 \%)$ & & & \\
\hline \multirow[t]{2}{*}{ Smoking } & Present & $53(22.9 \%)$ & $5(33.3 \%)$ & $48(22.2 \%$ & $1.67(0.60-4.69)$ \\
\hline & Absent & $178(77.1 \%)$ & & & \\
\hline \multirow[t]{2}{*}{ Urgent surgery } & Present & $16(6.9 \%)$ & $1(6.6 \%)$ & $15(6.9 \%)$ & $0.95(0.13-6.84)$ \\
\hline & Absent & $215(93,1 \%)$ & & & \\
\hline \multirow[t]{2}{*}{ Technical complications during surgery } & Present & $8(3.4 \%)$ & $1(6.6 \%)$ & $7(3.3 \%)$ & $1.99(0.29-13.34)$ \\
\hline & Absent & $223(96.6 \%)$ & & & \\
\hline \multirow[t]{2}{*}{ Alcohol-based surgical hand preparation } & Present & $99(42.8 \%)$ & $4(26.6 \%)$ & $95(43.9 \%)$ & $0.48(0.16-1.48)$ \\
\hline & Absent & $132(57.2 \%)$ & & & \\
\hline Extracorporeal circulation time $(\mathrm{min})^{\mathbf{a}}$ & & & $130(65-210)$ & $117(80-145)$ & $p=0.688$ \\
\hline ASA score ${ }^{\mathbf{a}}$ & & & $2(2-2)$ & $2(2-2)$ & $P=0.932$ \\
\hline Pre-operative length of stay (days) ${ }^{\mathbf{a}}$ & & & $3(1-7)$ & $2(1-6)$ & $p=0.356$ \\
\hline Duration of surgery (min) ${ }^{\mathbf{a}}$ & & & $195(129-285)$ & $190(125-261)$ & $p=0.778$ \\
\hline Body Mass Index - BMI ${ }^{\mathbf{a}}$ & & & $28.5(25.3-30.1)$ & $26.6(23.6-31.2)$ & $p=0.802$ \\
\hline
\end{tabular}

${ }^{\mathrm{a}}$ Median (interquartile range) 
Table 4 Multivariate statistical analysis (logistic regression) of risk factors for surgical site infections (SSI) among 150 patients operated in the study period

\begin{tabular}{lll}
\hline Variable & Odds ratio $(95 \% \mathrm{Cl})$ & $P$-value \\
\hline Alcohol-based surgical hand preparation & $0.66(0.16-2.70)$ & 0.563 \\
ASA score & $1.09(0.41-2.90)$ & 0.862 \\
Pre-operative length of stay (days) & $0.92(0.75-1.15)$ & 0.493 \\
\hline
\end{tabular}

Among those advantages, we can highlight less skin irritation, less time-consuming, economy of tap water, and more potent antimicrobial effect. However, only a few studies have attempted to implement and evaluate alcohol-based surgical hand preparation in a real world scenario $[17,18]$. The present study adds evidence on this topic, confirming some of the predicted benefits. The studied intervention consisted of making ABHR available in the operating room, training surgical teams for using it, promoting direct observation of the preparation, and providing them aggregated feedback on the quality of the preparation. That intervention was demonstrated effective for enhancing the quality of the preparation, and for shortening the time spent on the preparation. Regarding SSI prevention, the intervention was proven at least equivalent to the previous protocol, focused on the surgical scrub with antimicrobial soap.

An observational study of traditional surgical hand preparation by scrubbing with chlorhexidine solution detected unsatisfactory preparation, especially with respect to the mean scrubbing time, which was lower than the time advocated in the literature [13]. In another study. Nail scrubbing was observed in 33.7 and $41.5 \%$ for $2 \%$ chlorhexidine and 10\% PVPI solutions, respectively. Most healthcare professionals followed all the scrub steps during surgical hand preparation, which promoted an abrasive effect of scrub brush on their skin. This is the reason why the $\mathrm{WHO}$ does not recommend the use of scrub brushes [19, 20].

A study involving 156 healthcare professionals in southern Taiwan evaluated the microbial load reduction after surgical hand preparation and found that $A B H R$ had a highly persistent effect $(P=0.001)$ [12]. Another study verified an improved microbial load reduction when an ABHR was employed (1.91-1.52 $\log 10)$, as compared to chlorhexidine $(0.82-1.16 \log 10)$ and PVPI (0.52-0.92) solutions [21].

A systematic review of 14 randomized clinical trials compared the efficacy of chlorhexidine, PVPI, and ABHRs. ABHR was as effective as or more effective than antiseptic agent solutions. Nail scrubbing was the surgical hand asepsis step with the lowest evidence level. Moreover, the SSI rates were similar in all cases [17].

In a randomized clinical trial conducted in France between January 01 of 2000 and March 01 of 2001 with
4387 surgical patients, the SSI rates were similar for antiseptic agent solution and ABHR [55 cases (2.4\%) vs 53 cases $(2.48 \%)]$, respectively [18].

Our study presents some important limitations. First, a small imbalance was observed in some of the clinical and demographical features of the patients included in the pre- and in the intervention phases. However, none of those characteristics could affect the primary study outcome, and none of them was actually demonstrated to interfere with the secondary study outcome, in multivariate analysis. Second, compliance with post-discharge follow-up was greater in the pre-intervention than in the intervention period, which could lead to an underestimation of the SSI rate in the intervention period. Third, as the intervention was multifaceted, we are not able to infer the individual impact of each one of its components over the study outcomes.

\section{Conclusion}

The present study provides support for the routine use of ABHR for surgical hand preparation. Our results demonstrate that, when compared to the traditional surgical scrubbing with antimicrobial soap, alcohol-based surgical preparation, along with proper training, may improve the quality of the preparation, reduce the time spent on the preparation, and it is at least equally effective for the prevention of surgical site infections.

\section{Abbreviations}

95\% Cl: 95\% Confidence Interval; ABHR: Alcohol-Based Handrub; Adjusted RR: Adjusted Relative Risk; ASA: American Society of Anesthesiologists physical status classification system; BMI: Body Mass Index; PVPI: Povidone-lodine; SSI: Surgical Site Infection; WHO: World Health Organization

\section{Acknowledgements}

The authors thank the Infection Control Service team of the study facility for their assistance on the study implementation.

\section{Funding}

The University Hospital of the Ribeirão Preto Medical School provided the ABHR for the study. Other study costs were covered by a research grant issued by the World Health Organization Implementation Research Regional Training Centre for the Americas' Region.

\section{Availability of data and materials}

All data generated or analyzed during this study are included in this published article.

The anonymised datasets analysed during the current study are available from the corresponding author (GGG; ggaspar@hcrp.usp.br) on reasonable request, as long as this meets local ethics and research governance criteria.

\section{Authors' contributions}

Study concept and design: FBR; GGG. Acquisition of data: AN; TRA. Drafting of the manuscript: GGG; MGM; AERL. Statistical analysis: FBR; Critical revision of the manuscript for important intellectual content: GGG; MGM; AERL; ROCS; TRA; AN; LRF; MED; FBR; SRMSC. All authors read and approved the final manuscript.

Ethics approval and consent to participate

The study protocol was approved by the Research Ethics Committee by the Hospital das Clinicas of the Medical School of Ribeirão Preto, number 64964217.9.0000.5440. 


\section{Consent for publication}

Not applicable.

\section{Competing interests}

The authors declare that they have no competing interest. None of the authors have any conflicts of interest to disclose.

\section{Publisher's Note}

Springer Nature remains neutral with regard to jurisdictional claims in published maps and institutional affiliations.

\section{Author details}

'Infection Control Service, University Hospital of the Ribeirão Preto Medical School, University of São Paulo, Ribeirão Preto, SP, Brazil. ${ }^{2}$ Department of Surgery and Anatomy, Ribeirão Preto Medical School, University of São Paulo, Ribeirão Preto, SP, Brazil. ${ }^{3}$ Department of Fundamental Nursing, Ribeirão Preto College of Nursing, University of São Paulo, Ribeirão Preto, SP, Brazil. ${ }^{4}$ Hospital Administration, University Hospital of the Ribeirão Preto Medical School, University of São Paulo, Ribeirão Preto, SP, Brazil. ${ }^{5}$ Social Medicine Department, Ribeirão Preto Medical School, University of São Paulo, Ribeirão Preto, SP, Brazil. ${ }^{6}$ University Hospital of Ribeirão Preto Medical School, Avenida Bandeirantes, 3900 - Vila Monte Alegre, Ribeirão Preto, SP 14048-900, Brazil.

Received: 8 May 2018 Accepted: 29 June 2018

Published online: 09 July 2018

\section{References}

1. European Centre for Disease Prevention and Control. Point prevalence survey of healthcare-associated infections and antimicrobial use in European acute care hospitals. Stockholm: ECDC; 2013. Available from: https://ecdc.europa.eu/sites/portal/files/media/en/publications/Publications/ healthcare-associated-infections-antimicrobial-use-PPS.pdf

2. Magill SS, Hellinger W, Cohen J, et al. Prevalence of healthcare-associated infections in acute care hospitals in Jacksonville, Florida. Infect Control Hosp Epidemiol. 2012;33(3):283-91. https://doi.org/10.1086/664048.

3. WHO guidelines on hand hygiene in healthcare. Geneva: World Health Organization; 2009 (http://apps.who.int/iris/bitstream/handle/10665/44102/ 9789241597906_eng.pdf;jsessionid=8DFE9483D36DB1E696E2FD777FE FEC56? sequence=1. Accessed 20 Dec 2017).

4. Rotter ML. Arguments for alcoholic hand disinfection. J Hosp Infect. 2001:48(Suppl A):S4-8.

5. Widmer AF. Surgical hand hygiene: scrub or rub? J Hosp Infect. 2013; 83(Suppl 1):S35-9.

6. Hsieh HF, Chiu HH, Lee FP. Surgical hand scrubs in relation to microbial counts: systematic literature review. J Adv Nurs. 2006:55(1):68-78. 9.

7. Graf ME, Machado A, Mensor LL, Zampieri D, Campos R, Faham L. Surgical hands antisepsis with alcohol-based preparations: cost-effectiveness, compliance of professionals and ecological benefits in the Brazilian healthcare scenario (in Portuguese). J Bras Econ Saúde. 2014;6(2):71-80.

8. Hennign TJ, Werner S, Naujox K, Arndt A. Chlorhexidine is not an essential component in alcohol-based surgical hand preparation: a comparative study of two handrubs based on a modified EN 12791 test protocol. Antimicrob Resist Infect Control. 2017;6:96

9. Suchomel M, Gnant G, Weinlich M, Rotter M. Surgical hand disinfection using alcohol: the effects of alcohol type, mode, and duration of application. J Hosp Infect. 2009;71(3):228-33. https:/doi.org/10.1016/j.jhin.2008.11.006. Epub 2009 Jan 13

10. Chen SH, Chou CY, Huang JC, Tang YF, Kuo YR, Chien LY. Antibacterial effects on dry-fast and traditional water-based surgical scrubbing methods: a two-time points experimental study. Nurs Health Sci. 2014;16:179-85.

11. Peters DH, Tran NT, Adam T. Implementation research in health: a practical guide Alliance for Health Policy and Systems Research. Geneve: World Health Organization; 2013

12. Barbadoro $P$, Martin E, Savini S, Marigliano A, Ponzio E, Prospero E, D'Errico MM. In vivo comparative efficacy of three surgical hand preparation agents in reducing bacterial count. J Hosp Infect. 2014;86:64-7.

13. Pietsch HJ. Hand antiseptics: rubs versus scrubs, alcoholic solutions versus alcoholic gels. Hosp Infect. 2001;48(Suppl A):S33-6.
14. Marchetti MG, Kampf G, Finzi G, Salvatorelli GJ. Evaluation of the bactericidal effect of five products for surgical hand disinfection according to prEN 12054 and prEN 12791. Hosp Infect. 2003;54(1):63-7.

15. Lai KW, Foo TL, Low W, Naidu G. Surgical hand antisepsis-a pilot study comparing povidone iodine hand scrub and alcohol-based chlorhexidine gluconate hand rub. Ann Acad Med Singap. 2012;41(1):12-6.

16. Suchomel M, Kundi M, Allegranzi B, Pittet D, Rotter ML. Testing of the World Health Organization-recommended formulations for surgical handpreparation and proposals for increased efficacy. J Hosp Infect. 2011;79(2):115-8. https:// doi.org/10.1016/j.jhin.2011.05.005. Epub 2011 Jul 7

17. Gonçalves KJ; Graziano KU; Kawagoe JK. Revisão sistemática sobre antissepsia cirúrgica das mãos com preparação alcoólica em comparação aos produtos tradicionais. Rev. esc. enferm. USP vol.46 no.6 São Paulo Dec. 2012

18. Parienti JJ, Thibon P, Heller R, et al. Hand-rubbing with an aqueous alcoholic solution vs traditional surgical hand-scrubbing and 30-day surgical site infection rates: a randomized equivalence study. JAMA. 2002;288:722.

19. World Health Organization (WHO). WHO guidelines on hand hygiene in health care. First global patient safety challenge. Clean care is safe care, Geneva: World Health Organization (WHO); 2009.

20. Boyce JM, Pittet D. Guideline for Hand Hygiene in Health- Care Settings. Recommendations of the Healthcare Infection Control Practices Advisory Committee and the HICPAC/SHEA/ APIC/IDSA Hand Hygiene Task Force. Society for Healthcare Epidemiology of America/Association for Professionals in Infection Control/Infectious Diseases Society of America. MMWR Recomm Rep. 2002;51(RR-16):1-45. quiz CE1-4. https://www.cdc.gov/mmwr/PDF/ rr/rr5116.pdf pubmed/12418624

21. Tanner J, Dumville JC, Norman G, Fortnam M. Surgical hand preparation to reduce surgical site infection. Cochrane Database Syst Rev. 2016;(1)Art. No.: CD004288.

\section{Ready to submit your research? Choose BMC and benefit from:}

- fast, convenient online submission

- thorough peer review by experienced researchers in your field

- rapid publication on acceptance

- support for research data, including large and complex data types

- gold Open Access which fosters wider collaboration and increased citations

- maximum visibility for your research: over $100 \mathrm{M}$ website views per year

At BMC, research is always in progress.

Learn more biomedcentral.com/submissions 